\title{
Correction to: The SITCP26 promoting lateral branches development in tomato
}

\author{
Xiaoying Wei ${ }^{1}$. Jun Yang ${ }^{1} \cdot$ Dou Lei $^{1} \cdot$ Hao Feng ${ }^{1} \cdot$ Zhenan Yang $^{1} \cdot$ Guoqin Wen ${ }^{1} \cdot$ Zhuoyuan He $^{1} \cdot$ Wenjing Zeng $^{1}$. \\ Jian Zou ${ }^{1}$ (i)
}

Published online: 4 May 2021

○ The Author(s), under exclusive licence to Springer-Verlag GmbH Germany, part of Springer Nature 2021

\section{Correction to: Plant Cell Reports \\ https://doi.org/10.1007/s00299-021-02680-x}

In the Material and Methods section under the heading "Bioinformatics and homology analysis" the gene number of SITCP26 was incorrect in the original publication. The corrected sentence reads: "The sequence of SITCP26 gene (Solyc03g045030.1) was downloaded from tomato database (https://solgenomics.net/)."

The original article has been corrected.

Publisher's Note Springer Nature remains neutral with regard to jurisdictional claims in published maps and institutional affiliations.

The original article can be found online at https://doi.org/10.1007/ s00299-021-02680-x.

\section{Jian Zou}

zoujian@cwnu.edu.cn

1 Key Laboratory of Southwest China Wildlife Resources Conservation (Ministry of Education), College of Life Science, China West Normal University, Nanchong 637009, Sichuan, China 